\begin{tabular}{|c|l|}
\hline Title & Stereospecific Electrochemical Carboxylation of $\beta$-Bromostyrene by Use of Nickel(II) Catalyst \\
\hline Author(s) & Kuang, Chunxiang; Y ang, Qing; Senboku, Hisanori; Tokuda, Masao \\
\hline Citation & $\begin{array}{l}\text { Chemistry Letters, 34(4), 528-529 } \\
\text { https://doi.org/10.1246/li.2005.528 }\end{array}$ \\
\hline Issue Date & 2005-04.05 \\
\hline Doc URL & http://hdl.handle.net/2115/70909 \\
\hline Type & article \\
\hline File Information & cl.2005.528.pdf \\
\hline
\end{tabular}

Instructions for use 


\title{
Stereospecific Electrochemical Carboxylation of $\beta$-Bromostyrene by Use of Nickel(II) Catalyst
}

\author{
Chunxiang Kuang, ${ }^{* \dagger}$ Qing Yang, ${ }^{\dagger \dagger}$ Hisanori Senboku, ${ }^{\dagger \dagger}$ and Masao Tokuda ${ }^{\dagger \dagger \dagger}$ \\ †Department of Materials Chemistry, Graduate School of Engineering, Osaka University, Suita 565-0871 \\ ${ }^{\dagger}$ Department of Biopharmaceutics, Graduate School of Pharmaceutical Sciences, The University of Tokyo, Tokyo 113-0033 \\ ${ }^{\dagger}$ Division of Molecular Chemistry, Graduate School of Engineering, Hokkaido University, Sapporo 060-8628
}

(Received January 12, 2005; CL-050056)

Electrochemical carboxylation of $(E)$ - and $(Z)$ - $\beta$-bromostyrenes (1) under an atmospheric pressure of carbon dioxide with a platinum cathode and a magnesium anode in the presence of $20 \mathrm{~mol} \%$ of $\mathrm{NiBr}_{2} \cdot$ bpy proceeded with retention of stereochemistry to give the corresponding $(E)$ - or $(Z)$-cinnamic acids (2). The stereochemical outcome of nickel(II)-catalyzed electrochemical carboxylations was discussed by comparison with predominant formation of a $(Z)$-isomer from either $(E)$ - or $(Z)-\beta$ bromostyrenes.

Electrochemical carboxylation is one of the most useful methods for the fixation of carbon dioxide to organic molecules because it is a clean and environmentally benign process. It takes place efficiently even in an atmospheric pressure of $\mathrm{CO}_{2}$ under neutral and mild conditions to give carboxylic acids in high yields when a reactive-metal such as magnesium or aluminum is used as a sacrificial anode in the electrolysis. ${ }^{1}$ We have already reported that electrochemical carboxylation of vinyl halides and vinyl triflates gave the corresponding carboxylic acids in high yields. ${ }^{2}$ In 1996, we found that thermodynamically less-stable $(Z)$-cinnamic acids $((Z)-2)$ were preferentially produced from either $(E)$ - or $(Z)$ - $\beta$-bromostyrene $((E)$-1 or $(Z)$-1) in the electrochemical carboxylations. ${ }^{3}$ Electrochemical carboxylation of $(E)-\mathbf{1}$ gave a 30/70 mixture of $(E)-2$ and $(Z)-2$, whereas that of (Z)-1 also gave a 24/76 mixture of $(E)-\mathbf{2}$ and (Z)-2 (Scheme 1).

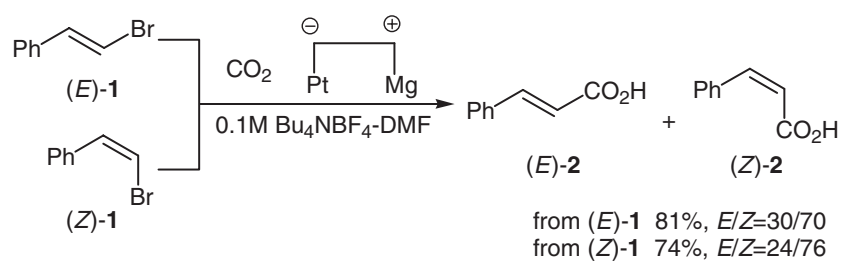

Scheme 1.

As one of our continuing studies on electrochemical carboxylation, we attempt to develop a novel route for the stereoselective electrochemical carboxylation of $(E)-\mathbf{1}$ and $(Z)-\mathbf{1}$ by use of nickel(II) catalyst. In this paper, we report our results concerning stereoselective electrochemical carboxylation and mechanistic aspects of this reaction.

We first examined the electrochemical carboxylation of $(E)-\mathbf{1}$ under various conditions. The results are summarized in Table 1. Various conditions were examined to optimize the yield and stereoselectivity. It was found that electrochemical carboxylation of $(E)-\mathbf{1}$ in the presence of $20 \mathrm{~mol} \%$ of nickel(II) bromide-2,2'-bipyridine complex $\left(\mathrm{NiBr}_{2} \cdot\right.$ bpy), at $-10^{\circ} \mathrm{C}$ and $5 \mathrm{~mA} / \mathrm{cm}^{2}$ of constant current with an electricity of 3 Faradays per mol of $(E)-\mathbf{1}$ gave the corresponding acid $\mathbf{2}(E / Z=99 / 1)$
Table 1. Electrochemical carboxylation of $(E)$ - $\beta$-bromostyrene $((E)-\mathbf{1})$ under various conditions ${ }^{\mathrm{a}}$

\begin{tabular}{ccccccc}
\hline Entry & $\begin{array}{c}\text { Catalyst } \\
\mathrm{NiBr}_{2} \cdot \text { bpy }\end{array}$ & $\begin{array}{c}\text { Temperature } \\
/{ }^{\circ} \mathrm{C}\end{array}$ & $\begin{array}{c}\text { Current } \\
\text { density } \\
/ \mathrm{mA} \mathrm{cm}^{-2}\end{array}$ & $\begin{array}{c}\text { Electricity } \\
/ \mathrm{F} \mathrm{mol}^{-1}\end{array}$ & $\begin{array}{c}\text { Yield } \\
/ \%{ }^{\mathrm{b}}\end{array}$ & $\begin{array}{c}\text { Isomer } \\
\text { ratio } \\
E / Z^{\mathrm{c}}\end{array}$ \\
\hline 1 & - & 5 & 10 & 3 & 81 & $30 / 70$ \\
2 & - & -10 & 10 & 3 & 61 & $21 / 79$ \\
3 & $10 \mathrm{~mol} \%$ & -10 & 10 & 3 & 66 & $78 / 22$ \\
4 & $20 \mathrm{~mol} \%$ & -10 & 10 & 3 & 65 & $88 / 12$ \\
5 & $20 \mathrm{~mol} \%$ & -10 & 15 & 3 & 47 & $67 / 33$ \\
6 & $20 \mathrm{~mol} \%$ & -10 & 5 & 3 & 71 & $99 / 1$ \\
7 & $20 \mathrm{~mol} \%$ & 20 & 10 & 3 & 72 & $91 / 9$ \\
8 & $20 \mathrm{~mol} \%$ & -10 & 5 & 4.5 & 76 & $77 / 23$ \\
\hline
\end{tabular}

${ }^{\mathrm{a}}(E)$ - $\beta$-bromostyrene $(3 \mathrm{mmol})$ in $0.1 \mathrm{M} \mathrm{Bu}_{4} \mathrm{NBF}_{4}-\mathrm{DMF}(15 \mathrm{~mL})$ was electrolyzed in the presence of $20 \mathrm{~mol} \%$ of $\mathrm{NiBr}_{2} \cdot$ bpy under an atmospheric carbon dioxide with a Pt cathode and a Mg anode. ${ }^{\mathrm{b}}$ Isolated yields. ${ }^{\mathrm{c}}$ Isomer ratios were determined by ${ }^{1} \mathrm{HNMR}$.

with retention of its stereochemistry in a $71 \%$ yield (Table 1 , Entry 6).

Similar nickel-catalyzed electrochemical carboxylation of $(Z)-\mathbf{1}$ under the same condition as that of $(E)$-1 gave the corresponding acid $2(E / Z=1 / 99)$ in a $78 \%$ yield (Scheme 2$).{ }^{4}$ The use of an aluminum or zinc anode, instead of magnesium anode, in the electrochemical carboxylation of $(E)-\mathbf{1}$ resulted in a decreased yield and stereochemistry of the acid 2. Electrochemical carboxylation of $(E)-\mathbf{1}$ in the presence of $20 \mathrm{~mol} \%$ of $\mathrm{NiBr}_{2} \cdot$ bpy, using a platinum cathode and an aluminum anode gave a 76/24 mixture of (E)-2 and (Z)-2 only in a $45 \%$ yield. Additionally, electrochemical carboxylation of $(E)-\mathbf{1}$ using a zinc anode gave a mixture of acid $2(E / Z=73 / 27)$ in only a $9 \%$ yield. These results show that a magnesium anode plays an important role in efficient electrochemical carboxylation and its stereochemistry. It was also found that palladium catalyst such as $\mathrm{Pd}\left(\mathrm{PPh}_{3}\right)_{4}, \mathrm{PdCl}_{2}\left(\mathrm{PPh}_{3}\right)_{2}$ were not effective in this reaction.

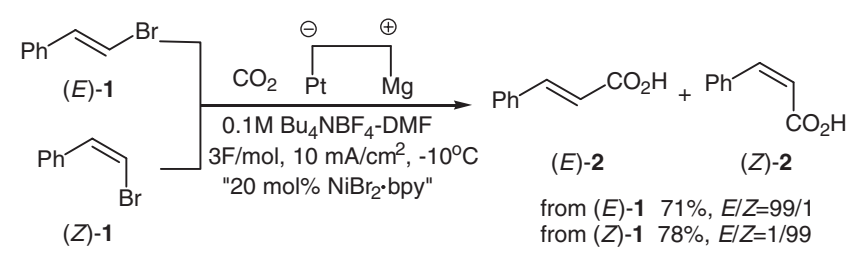

Scheme 2 .

The present electrochemical method is useful for the synthesis of substituted $(E)$ - or $(Z)$-cinnamic acids since the starting $(E)$ - or (Z)-vinyl bromides can readily be prepared in high yields. ${ }^{5}$ The electrochemical carboxylation of $(Z)$-vinyl bromides with $\mathrm{CO}_{2}$ has especially been proposed as a useful proce- 
dure for the production of $(Z)$-cinnamic acids which are difficult to prepare by conventional method, ${ }^{6 \mathrm{a}}$ even though the conversion of $(E)$-cinnamic acids to its $(Z)$-isomer has been reported. ${ }^{6 \mathrm{~b}}$

The probable reaction pathways of the present electrochemical carboxylation are shown in Scheme 3. At the cathode, in the presence of nickel catalyst, a two-electron reduction of $\mathrm{NiBr}_{2}$. bpy gives $\mathrm{Ni}(0)$ species, and an oxidative addition of the $\mathrm{Ni}(0)$ to $(E)$ - or $(Z)-\mathbf{1}$ would produce the intermediate $\mathbf{A}$ or $\mathbf{B}$, isomerization could not occur between $\mathbf{A}$ and $\mathbf{B}$ at this stage. A twoelectron reduction of $\mathbf{A}$ or $\mathbf{B}$ gives the corresponding vinyl carbanion $(\mathbf{C}$ or $\mathbf{D})$, which is trapped by atmospheric carbon dioxide to give the corresponding alkenoate $(\mathbf{E}$ or $\mathbf{F})$. At the anode, on the other hand, a dissolution of magnesium metal takes place to give magnesium ion. The magnesium ion readily captures 2-alkenoates ( $\mathbf{E}$ or $\mathbf{F}$ ) to give the stable magnesium carboxylate $\mathbf{I}$ or $\mathbf{J}$. Acid treatment of $\mathbf{I}$ or $\mathbf{J}$ gives $(E)-\mathbf{2}$ or $(Z)-\mathbf{2}$. Cyclic voltammetry of $(E)-\mathbf{1}$ and $(Z)-\mathbf{1}$ in the presence of $\mathrm{NiBr}_{2} \cdot$ bpy showed the existence of an additional reduction peak at ca. -1.98 and $-1.97 \mathrm{~V}$ vs $\mathrm{Ag} / \mathrm{AgCl}$, respectively, while the reduction peaks of $(E)-\mathbf{1},(Z)-\mathbf{1}$ and $\mathrm{NiBr}_{2} \cdot$ bpy alone appeared at $-2.59,-2.62$, and $-1.53 \mathrm{~V}$, respectively. ${ }^{7}$ These result suggest that in the presence of $\mathrm{NiBr}_{2} \cdot$ bpy, a direct two-electron reduction of intermediate $\mathbf{A}$ or $\mathbf{B}$ may take place preferentially over a one-electron reduction giving an equilibration between two $(E)$ - and (Z)-vinyl radical.

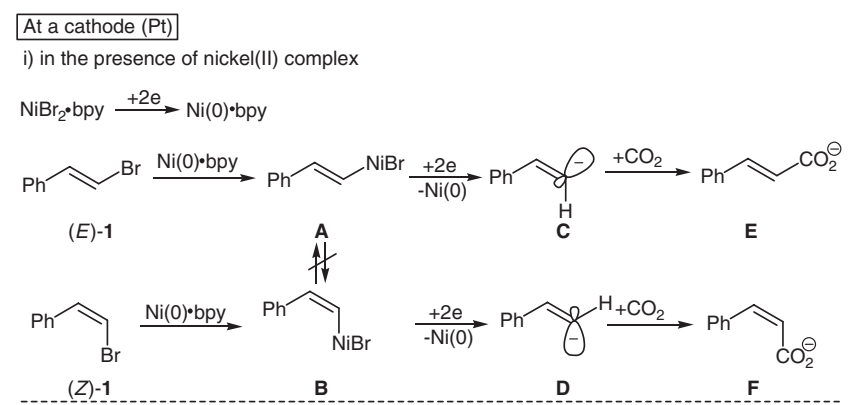

ii) in the absence of nickel(II) complex
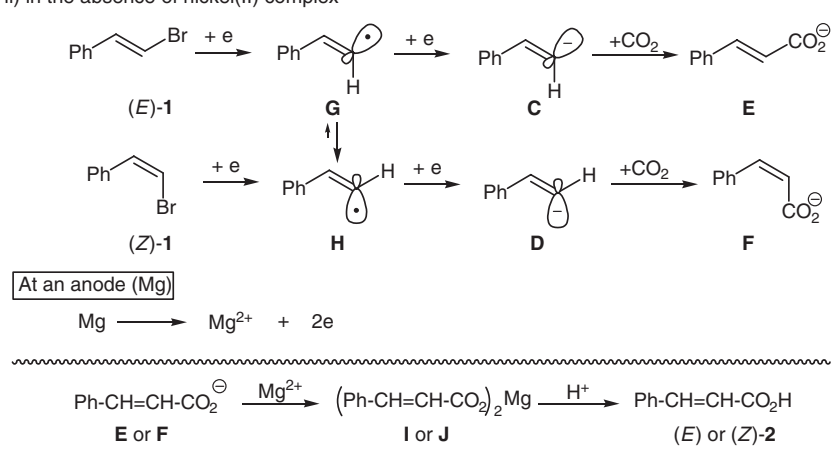

Scheme 3.

In the absence of nickel catalyst, a one-electron reduction of $(E)$ - or $(Z)-\mathbf{1}$ gives the corresponding vinyl radical $\mathbf{G}$ or $\mathbf{H}$, respectively (Scheme 3). In an equilibration between vinyl radicals $\mathbf{G}$ and $\mathbf{H}$, the radical $\mathbf{H}$ would gain an advantage over radical $\mathbf{G}$ due to some interaction of a magnesium ion with a phenyl group and a radical center. When a platinum anode, instead of a magnesium anode, was used in the electrochemical carboxylation of $(E)-\mathbf{1},(E)-\mathbf{2}$ was predominantly produced. This result indicates that a magnesium ion, formed by dissolution of a magne- sium anode in electrolysis, plays an important role in the $(Z)$-selectivity of electrochemical carboxylation of vinyl bromides. In order to find a further evidence of this prospect, we investigated the electrochemical carboxylation of (Z)-1-bromo-3-cyclohexylethylene $((Z)-3)$ in the absence of nickel catalyst, much to our delight, a 51/49 mixture of $(E)$ - and (Z)-3-cyclohexylpropenoic acid ((E)- and (Z)-4) was obtained in a $23 \%$ yield. Because of an absence of $\pi$-electron in cyclohexyl group, stability of the two vinyl radicals is not so different, hence electrochemical carboxylation of (Z)-3 gave the (E)- and (Z)-4 in almost same ratio. These results showed that both $\pi$-electron of phenyl group and magnesium ion are essential in regulation of the stereoselectivity of electrochemical carboxylation of vinyl bromides.

In summary, we have developed a novel route for the stereoselective electrochemical carboxylation of $\beta$-bromostyrene by use of nickel(II) catalyst. The stereochemical mechanistic aspects of nickel(II)-catalyzed electrochemical carboxylations are discussed by comparison with predominant formation of a $(Z)$-isomer from either ( $E)$ - or $(Z)$ - $\beta$-bromostyrenes.

This work was supported by a Grant-in-Aid for Scientific Research (A) (No. 07555580) from The Ministry of Education, Culture, Sports, Science and Technology, Japan.

\section{References and Notes}

1 a) G. Silvestri, S. Gambino, G. Filardo, and A. Gulotta, Angew. Chem., Int. Ed. Engl., 23, 979 (1984). b) O. Sock, M. Troupel, and J. Périchon, Tetrahedron Lett., 26, 1509 (1985).

2 a) H. Kamekawa, H. Kudoh, H. Senboku, and M. Tokuda, Chem. Lett., 1997, 917. b) H. Kamekawa, H. Senboku, and M. Tokuda, Tetrahedron Lett., 39, 1591 (1998). c) H. Senboku, H. Kanaya, Y. Fujimura, and M. Tokuda, J. Electroanal. Chem., 507, 82 (2001).

3 H. Kamekawa, H. Senboku, and M. Tokuda, Electrochim. Acta, 42, 2117 (1997).

4 Typical procedure for the nickel(II)-catalyst electrochemical carboxylation of $\beta$-bromostyrene is described in the followings: A mixture of $(E)-\beta$-bromostyrene $((E)-\mathbf{1}, 3 \mathrm{mmol})$ and $\mathrm{NiBr}_{2} \cdot$ bpy $(0.6 \mathrm{mmol})$ and $\mathrm{Bu}_{4} \mathrm{NBF}_{4}(1.5 \mathrm{mmol})$ in $15 \mathrm{~mL}$ of DMF was added into a one-compartment cell equipped with a platinum plate cathode $\left(2 \times 3 \mathrm{~cm}^{2}\right)$ and a magnesium rod anode $(3 \mathrm{~mm} \phi)$. The mixture was electrolyzed at $-10^{\circ} \mathrm{C}$ at $5 \mathrm{~mA} / \mathrm{cm}^{2}$ of constant current under a slow stream of carbon dioxide gas until an electricity of 3 Faradays per mol of $(E)-\mathbf{1}$ was passed. The electrolyzed solution was poured into $2 \mathrm{~N} \mathrm{HCl}$ and extracted with diethyl ether $(3 \times 50$ $\mathrm{mL})$. After the organic layer was washed with water $(4 \times 50 \mathrm{~mL})$, it was extracted by saturated sodium hydrogen carbonate $(3 \times$ $50 \mathrm{~mL}$ ). The aqueous layer was again acidified with $2 \mathrm{~N} \mathrm{HCl}$ and extracted with diethyl ether $(3 \times 50 \mathrm{~mL})$. The organic layer was washed with brine and dried over MgSO4. Filtration and evaporation of the solvent afforded cinnamic acid $2(E / Z=99 / 1)$ in $71 \%$ yield. Mp $133-134{ }^{\circ} \mathrm{C} ;{ }^{1} \mathrm{HNMR}\left(270 \mathrm{MHz}, \mathrm{CDCl}_{3}\right) \delta 6.46(1 \mathrm{H}, \mathrm{d}$, $J=16.1 \mathrm{~Hz}), 7.39-7.44(3 \mathrm{H}, \mathrm{m}), 7.52-7.57(2 \mathrm{H}, \mathrm{m}), 7.80(1 \mathrm{H}, \mathrm{d}$, $J=16.1 \mathrm{~Hz}) ;{ }^{13} \mathrm{CNMR}\left(67.5 \mathrm{MHz}, \mathrm{CDCl}_{3}\right) \delta 117.30,128.35$, 128.93, 130.72, 133.98, 147.09, 172.66.

5 a) C. Kuang, H. Senboku, and M. Tokuda, Synlett, 2000, 1439. b) C. Kuang, H. Senboku, and M. Tokuda, Tetrahedron Lett., 42, 3893 (2001). c) C. Kuang, H. Senboku, and M. Tokuda, Tetrahedron, 58, 1491 (2002). d) C. Kuang, H. Senboku, and M. Tokuda, Tetrahedron, 61, 637 (2005), and references cited therein.

6 a) M. B. Hocking, Can. J. Chem., 47, 4567 (1969). b) V. Galamb and H. Alper, Tetrahedron Lett., 24, 2965 (1983).

7 Reduction peak potentials of $(E)$ - and $(Z)-\beta$-bromostyrene and $\mathrm{NiBr}_{2} \cdot$ bpy were determined by cyclic voltammetry of $2 \mathrm{mM}$ substrates in $0.1 \mathrm{M} \mathrm{Bu}_{4} \mathrm{BF}_{4}$-DMF with a gold disk electrode (1.6 $\mathrm{mm} \phi$ ) at the scan rate of $0.1 \mathrm{~V} / \mathrm{s}$. 